\title{
PÓS-POSITIVISMO E ARGUMENTAÇÃO JURÍDICA: REFLEXÃO À LUZ DO CONCEITO DE DIREITO
}

Hugo Garcez Duarte*

Sumário: 1 Introdução; 2 O Positivismo Jurídico; 3 Pós-positivismo Jurídico; 4 Teoria da Argumentação Jurídica; 5 Conclusão.

Resumo: O artigo visa analisar a proposta hodierna de conciliação entre validade formal e validade material (legitimidade). Para tal, discorremos sobre as teorias Positivista e Pós-positivista do Direito, perpassando os ditames da Escola da Exegese, tendo demonstrado que o conceito de Direito alterou-se de acordo com o paradigma adotado. Esta última encarou o Direito como ciência completa, sem lacunas, apta a resolução de todos os fatos da vida por meio da aplicação literal da lei. A primeira sucedeu-a com uma nova proposta, evidenciando o caráter discricionário de aplicação do Direito bem como sua indeterminação. A segunda, por sua vez, propõe-se a resolver os problemas que envolvem o poder discricionário do juiz e a indeterminação do Direito, não resolvidos pela primeira. Nesse sentido, suscitamos a teoria de Robert Alexy que, baseado no papel exercido pelos princípios e na argumentação jurídica, aponta o procedimento do Direito como parte de seu conceito.

Palavras-chave: Pós-positivismo. Poder discricionário. Determinação do Direito. Princípios. Argumentação jurídica.

\footnotetext{
Mestre em Teoria do Direito - Hermenêutica e Direitos Fundamentais pela Universidade Presidente Antônio Carlos de Juiz de Fora/MG. Especialização em Direito Público pela Universidade Cândido Mendes/RJ. Graduação em Direito pela Universidade Estácio de Sá de Nova Friburgo/RJ. Professor de Direito Constitucional e Coordenador do Curso de Direito da Faculdade de Direito e Ciências Sociais do Leste de Minas de Reduto/MG.
} 


\section{Introdução}

O artigo faz uma digressão acerca do conceito de Direito. Analisamos primeiramente os preceitos do Positivismo, estabelecendo suas distinções com os defendidos pela Escola da Exegese.

Desenvolvemos que, apesar de tratar-se de uma teoria extremamente formal, em Kelsen e Hart, principalmente, há o reconhecimento do poder discricionário do juiz, que, atrelado à norma, terá uma margem (por meio dos princípios) de apreciação na busca da melhor maneira de se resolver dado caso. Entretanto, não há resolução de tais problemas, por mais que tenha apresentado uma teoria diversa do legalismo exacerbado defendido pela Escola da Exegese, a qual reduzira o Direito à lei escrita, concebendo-o de uma maneira completa, imputando ao julgador a efetivação dos ditames legais, ou seja, o papel de boca que pronuncia os mandamentos legais.

Posteriormente, fomentamos a teoria Pós-positivista do Direito, tendo procurado estabelecer que a pretensão de superação do Positivismo Jurídico, dominante no século XX, concentra-se na resolução do problema que envolve o poder discricionário do julgador, bem como o da determinação do Direito no caso concreto, de modo a alcançar a conciliação entre validade formal e validade material (legitimidade).

Almejando a resolução de referidos problemas, concebemos Robert Alexy como Pós-positivista, por apresentar considerável alternativa para a celeuma.

Para o autor, o conceito de Direito engloba além de preceitos também defendidos pelo Positivismo jurídico a pretensão à correção material, que poderá ser conquistada a partir do procedimento do Direito, com ênfase no papel exercido pelos princípios e na argumentação jurídica.

\section{O Positivismo Jurídico}

O que se deve considerar como direito e a maneira mais adequada de aplicá-lo são questões que, há muito, protagonizam discussões no cenário jurídico. Encontrar respostas não é tarefa das mais fáceis, mas tentativas não faltam, modificando-se o paradigma conforme o momento histórico vivido. Hodiernamente, a denominada Teoria Pós-Positivista do Direito propõe solução à celeuma, almejando a superação do Positivismo Jurídico que dominara a ciência jurídica no século XX.

Referida teoria pretenderia, para tal, combater características supostamente atribuídas ao Positivismo Jurídico, que teria defendido a inexistência de princípios (ou desprovimento de caráter normativo 
dos princípios), tendo pregado que o Direito é um modelo de regras; a completude do Direito, isto é, a inexistência de lacunas; a supremacia da lei ordinária sobre a Constituição; e a aplicação do Direito de forma mecânica, consubstanciada na subsunção.

Ocorre que, tais características coadunam-se, propriamente, com o legalismo da escola francesa da Exegese do século XIX, pois o Positivismo Jurídico defende posicionamentos totalmente contrários.

A Escola da Exegese, que teve como marco o Código Napoleônico de 1804, asseverava que Direito reduzir-se-ia à lei escritas, por prever em seu corpo os princípios superiores, eternos, uniformes, permanentes e imutáveis sustentados pela Escola Jusnaturalista do Direito.

Para os adeptos desta Escola, a lei era obra jurídica perfeita, completa, abarcando o "verdadeiro direito", reprodução escrita dos valores absolutos de justiça do Direito Natural, insculpidos na vontade do legislador.

Tal concepção reduziu o juiz ao papel de burocrático aplicador de leis, encarando o ordenamento jurídico como um “catálogo", dotado da previsão de todos os fatos ocorridos e que viessem a ocorrer na sociedade, que com sua consecução subsumir-se-iam a ele. Ou seja, vedava-se aos juízes o poder de criação, sendo-lhes reservada, tão-somente, a incumbência de verdadeira boca que pronuncia os ditames legais.

Sua atividade seria meramente silogística, eis que a lei era encarada como premissa maior e o fato como premissa menor, donde desta conjugação chegava-se a uma decisão lógico-dedutiva.

Posteriormente, tal concepção acerca do Direito foi contestada, sendo a Escola Histórica a primeira a fazê-lo, sustentando a inexistência de um direito geral e universal, visto que cada povo, em cada época, teria o seu próprio direito resultante de sua evolução histórica, de seus usos, costumes e tradições.

Esforçaram-se os defensores desta Escola em demonstrar que o direito era um produto histórico, sujeito a permanente e natural evolução, nem estabelecido arbitrariamente pela vontade dos homens, nem emanado de Deus, mas pela consciência coletiva do povo.

Nesses moldes, entende-se que a lei não é pronta e acabada, estando suscetível a uma interpretação mais ampla do que a defendida pela Escola da Exegese, imputando-se ao intérprete, além da função de esclarecimento dos ditames legais, a promoção de sua contextualização com os interesses e necessidades sociais, de modo que desvende como agiria o legislador, caso estivesse em seu lugar prestes a solucionar um caso. 
Já no século XX, o Positivismo Jurídico apresenta, também, uma teoria diversa da legalista sustentada pela Escola da Exegese. Tal teoria, de caráter extremamente formal, teria pregado, supostamente, a separação entre o Direito e a moral (teoria da neutralidade ou da separação), concebendo o Direito de uma maneira neutra, como uma estrutura lógico-formal, desprovida de qualquer conexão com a moral.

Dissemos supostamente pelo fato de que, como notaremos a seguir, no que diz respeito à interpretação do Direito, bem como sua aplicação, grandes Positivistas como Kelsen e Hart desenvolvem suas teorias admitindo a discricionariedade do julgador, que vinculada à norma jurídica, por vezes irá transcendê-la exercendo verdadeiro ato de criação do Direito, despertando-nos, por consequência, a reflexão: de quais elementos faria uso o julgador para transcender a norma jurídica em seu ato de criação do Direito? Seria a moral? Vejamos as teorias.

Kelsen aponta que a aplicação do Direito encontra-se carreada de uma forma relativamente indeterminada, havendo relação entre normas de escalão superior e normas de escalão inferior. ${ }^{1}$

Segundo este, a norma de escalão superior determina a execução, bem como o conteúdo da norma inferior. ${ }^{2}$ Todavia, essa orientação se dá de um modo incompleto:

\footnotetext{
A norma do escalão superior não pode vincular em todas as direções (sob todos os aspectos) o ato do qual é aplicada. Tem sempre de ficar uma margem, ora maior ora menor, de livre apreciação, de tal forma que a norma do escalão superior, tem sempre, em relação ao ato de produção normativa ou execução que aplica, o caráter de um quadro ou moldura a preencher por este ato. Mesmo uma ordem mais pormenorizada possível tem de deixar àquele que a cumpre ou executa uma pluralidade de determinações a fazer (KELSEN, 2006, p. 388).
}

Na Teoria Positivista de Kelsen, o juiz, quando da aplicação do Direito, deverá, além de seguir a lei (norma de escalão superior), observar as diversas alternativas de interpretação possibilitadas por esta moldura, de modo a apontar, na norma de escalão inferior (sentença), a melhor maneira de solucionar dado caso, de acordo com suas peculiaridades.

Todavia, inadmite o mesmo, no que tange a busca do melhor modo de julgar-se o caso concreto, que qualquer conteúdo seja considerado como Direito. Momento em que, eventual preenchimento de lacunas estaria vinculado, pelo que chama de interpretação autêntica, à atuação

\footnotetext{
KELSEN, 2006, p. 388.

2 Idem.
} 
do órgão jurídico aplicador do Direito. De outro modo, demais tipos de interpretação, como a cognoscitiva da ciência jurídica, estabeleceriam, tãosomente, "possíveis significações de uma norma jurídica" (Idem, p. 395).

Hart, por sua vez, argumenta que na sociedade haveria necessidade de delimitar-se padrões e princípios de conduta difusos, e que o Direito, por não regular de forma específica a conduta de cada indivíduo, mas de classes de pessoas e de atos, para fazê-lo, utiliza-se de dois instrumentos: a legislação e o precedente. Por legislação, entende-se aquela forma normativa definidora de um padrão de conduta como modelo obrigatório, de modo que o precedente apresenta-se como uma referência de conduta. ${ }^{3}$

Por mais que tenha denominado tais figuras normativas, Hart reconhece a impossibilidade da previsão, pelo legislador, de todos os fatos da vida, tendo fomentado que a aplicação do Direito é envolvida por uma gama de alternativas, classificando de textura aberta do Direito a possibilidade de que, em razão das circunstâncias, autoridades judiciais e administrativas evidenciem um equilíbrio entre interesses em conflito, cujo peso varia em virtude das particularidades de cada caso. ${ }^{4}$ Hart assevera a existência de uma margem, ou seja, como Kelsen, admite espaços deixados em aberto para que o aplicador do Direito busque a melhor forma de julgar determinado caso:

\footnotetext{
Se o mundo no qual vivemos tivesse apenas um número finito de características, e estas, juntamente com todas as formas sob as quais podem se combinar, fossem conhecidas por nós, poderíamos então prever de antemão todas as possibilidades. Poderíamos criar normas cuja aplicação a casos particulares nunca exigiria uma escolha adicional. Poder-se-ia tudo saber e, como tudo seria conhecido, algo poderia ser feito em relação a todas as coisas e especificado antecipadamente por uma norma. Esse seria um mundo adequado a uma jurisprudência "mecânica". Esse não é, evidentemente, o nosso mundo; os legisladores humanos não podem ter o conhecimento de todas as combinações possíveis de circunstâncias que o futuro pode trazer [...] (HART, 2009, p. 166-167).
}

Extrai-se do referido a percepção de ambos autores que a aplicação do Direito é carreada de criação, deixando claro que o julgador, atendo-se às minúcias do fato, além de julgá-lo aplicando o modelo obrigatório de conduta (norma jurídica), fomenta-o.

Além disso, nos resta evidente, manifestarem-se de formas totalmente distintas as premissas da Escola legalista da Exegese e da Teoria Positivista do Direito, pois enquanto a primeira defende uma interpretação mecânica

\footnotetext{
O autor desenvolve o raciocínio em HART, 2009, p. 161-162.

4 Idem, p. 175.
} 
do Direito, em que somente ao legislador é atribuída a tarefa de criar Direito, a segunda tende a rechaçá-la, por considerar o aplicador do Direito, além do legislador, um criador deste.

Contudo, não nos parece claro o que a Teoria Pós-Positivista do Direito pretende superar em realidade no Positivismo Jurídico. Seria a hipotética separação entre Direito e Moral constantemente argumentada? Haja vista que as características outrora anunciadas são, igualmente, combatidas pelo Positivismo Jurídico. É o que buscaremos desenvolver no próximo capítulo quando examinaremos a Teoria Pós-Positivista do Direito.

\section{Pós-positivismo Jurídico}

A Teoria Pós-positivista do Direito propõe solução para o legado deixado pelo Positivismo Jurídico, que não resolveu o problema da determinação do Direito no caso concreto, bem como o que envolve o poder discricionário do julgador.

Pretenderia a promoção do reencontro da ética com o Direito, por meio de um conjunto de ideias difusas, inovando sua aplicação sem substituíla, combatendo, entretanto, o poder discricionário pregado por autores como o normativista Kelsen e também por Hart, sem, contudo, voltar ao legalismo mecanicista da Escola da Exegese do século XIX, bem como fazer uso dos metafísicos preceitos da Escola Jusnaturalista. ${ }^{5}$

Para alguns teóricos, como Luís Roberto Barroso, suas principais marcas são a ascensão dos valores e o reconhecimento da normatividade dos princípios, fundamentando que a dogmática tradicional fomentou-se sob o mito da objetividade do Direito e da neutralidade do intérprete, tendo encoberto seu caráter ideológico, bem como sua instrumentalidade à dominação econômica e social. ${ }^{6}$ Vale dizer, todavia, existirem controvérsias quanto ao referido, pois o Positivismo Jurídico como veremos a seguir concebe os princípios como normas e não defende a neutralidade do intérprete.

Concordamos, inicialmente, que o legalismo manifesto na prática jurídica (principalmente) precisa ser superado, eis que, realmente, ideologias foram encobertas em nome da lei e a favor de uma dominação econômica e social. Entretanto, discordamos de quem denomina tais ações como fruto do Positivismo Jurídico, pois há, como demonstramos no capítulo anterior, nos pensamentos de dois dos maiores positivistas (Kelsen e Hart), a defesa de teses contrárias ao referido. Ora, uma coisa

\footnotetext{
5 Sobre o reencontro da ética com o Direito indicamos a leitura de BARROSO, 2006, p. 47.

6 Idem.
} 
é a criatura, outra coisa é o nome que se dá a esta criatura.

O Positivismo, conforme vimos, em ambos os autores, admite que o legislador, como ser humano que o é e não Deus, não pode prever todas as minúcias do viver. Pois as normas têm um condão de indeterminação, servindo unicamente como uma moldura a ser preenchida pelo intérprete, que investigará a melhor maneira da resolução do caso concreto. Diversamente da Escola da Exegese do século XIX, que pregava a completude da lei bem como a aplicação mecânica, sob o crivo da subsunção.

Que a aplicação do direito, em nosso tempo, se deu de uma maneira legalista, havendo necessidade de uma lapidação, é fato. Todavia, há de reconhecer-se que tal realidade (legalismo exacerbado) coaduna-se com a escola legalista da Exegese, aplicada sob o manto do Positivismo Jurídico. Vale dizer que a Teoria Positivista do Direito é estigmatizada por elementos que não the são peculiares, pois o legalismo exacerbado por nós vislumbrado representa em verdade os ditames doutrinários da Escola da Exegese e não os preceitos daquela.

Tanto Kelsen, quando trata da generalidade da norma, como Hart quando trata da textura aberta do Direito, reconheceram o papel criador do intérprete do Direito, que por vezes, em atendimento às circunstâncias do caso, deverá transcender a lei, que se aplicada de forma literal, não corresponderá aos anseios deste.

Como haveria neutralidade do intérprete no Positivismo Jurídico se ao mesmo tempo é reconhecido o poder discricionário e a possibilidade de criação do Direito? A neutralidade que o Positivismo Jurídico sustenta é da ciência do Direito (e não do intérprete do Direito ou do próprio Direito), significando inexistir subordinação entre este e uma moral específica. Ou seja, para o Positivista, o Direito encontra-se desvinculado de uma moral determinada, sendo descrito de uma maneira puramente formal.

Neste sentido vale observar:

Quando uma teoria do Direito positivo se propõe distinguir Direito e Moral em geral e Direito e Justiça em particular, para não os confundir entre si, ela volta-se contra a concepção tradicional, tida como indiscutível pela maioria dos juristas, que pressupõe que apenas existe uma única Moral válida - que é, portanto, absoluta - da qual resulta uma Justiça absoluta. A exigência de uma separação entre Direito e Moral, Direito e Justiça, significa que a validade de uma ordem jurídica positiva é independente desta Moral absoluta, única válida, da Moral por excelência, de a Moral (KELSEN, 2006, p. 75).

Kelsen, com tais palavras, ao que parece, visou demonstrar que o Direito não está vinculado a uma moral pré-determinada, a uma moral 
absoluta. Para o professor, o justo não pode ser prévia e arbitrariamente determinado, pois por meio de juízos de valor (relativos) pode-se vincular o Direito a diversos valores, muitas vezes opostos.

No que tange referida relatividade Kelsen asseverou que:

Se pressupusermos somente valores morais relativos, então a exigência de que o Direito deve ser moral, isto é, justo, apenas pode significar que o Direito positivo deve corresponder a um determinado sistema de Moral entre os vários sistemas morais possíveis. Mas com isso não fica excluída a possibilidade da pretensão que exija que o Direito positivo deve harmonizar-se com um outro sistema moral e com ele venha eventualmente a concordar de fato, contradizendo um sistema moral diferente deste (Idem).

E a normatividade dos princípios? Como poderemos negar a existência de princípios bem como defender o desprovimento de sua normatividade no Positivismo Jurídico diante da norma geral de Kelsen e da textura aberta do Direito de Hart, se são exatamente esses tipos de normas que, por seu caráter abstrato, autorizam o papel criador do aplicador do Direito? Se o Direito encontra-se desvinculado a uma moral determinada, abarcando diversas concepções morais, como identificaremos à luz do caso concreto o Direito justo, senão por meio dos princípios (que são normas)?

Tais premissas refletem, por mais que se trate de uma teoria extremamente formal, que no Positivismo Jurídico existem princípios e que eles são considerados normas. Em nosso sentir, o problema da legitimidade do Direito, que o Pós-positivismo pretende superar no Positivismo Jurídico, não reside na inexistência e/ou ausência de normatividade dos princípios neste último, mas sim, no papel exercido pelos mesmos em ambas teorias.

No Positivismo Jurídico, os princípios são encarados como justificativa do poder discricionário do julgador, porquanto que, no Pós-positivismo Jurídico serviriam de meio para superação dessa discricionariedade.

Essa evidência reflete-se na fundamentação do Direito e em sua adequação. No Positivismo Jurídico, o fundamento de validade do Direito é formal, e por ser formal, sua adequação é indeterminada. O Pós-positivismo por sua vez, em busca da determinação do Direito, consubstancia-se na conciliação entre validade formal e validade material (legalidade e legitimidade).

Grande desafio, porém, é a conquista da conciliação entre validade formal e validade material sem voltar ao dogmatismo jusnaturalista. Tal conciliação, ao que parece, coaduna-se com o aludido papel dos princípios, que na teoria Pós-positivista, diversamente da teoria Positivista (justificava o poder discricionário do juiz), assume o papel de elo (por meio da 
argumentação jurídica) entre o legal e o justo.

Não temos, nesse humilde ensaio, a pretensão de estabelecer os caminhos da conciliação entre o legal e o justo, mas procuraremos desenvolver a seguir, o papel dos princípios e da argumentação jurídica nessa jornada.

\section{Teoria da Argumentação Jurídica}

No ponto anterior, pudemos constatar que a proposta Pós-positivista pretende superar, em verdade, no Positivismo Jurídico, os problemas por este não resolvidos envolvendo a determinação do Direito no caso concreto, além do poder discricionário do julgador.

Notamos, diversamente do que se pregou em referência ao Positivismo Jurídico, por mais que se tratasse de uma teoria extremamente formal, há neste, o reconhecimento de princípios e que são considerados normas. Além de que, é exatamente este o ponto determinante de transição da Teoria Positivista para a Pós-positivista do Direito. Ou seja, que na primeira teoria, os princípios eram elementos justificadores do poder discricionário do julgador, e neste último, realizam uma "ponte" para a superação dessa discricionariedade.

Os elementos dessa transição remontam-nos a outro problema, que envolve a fundamentação do Direito e sua adequação, pois, no Positivismo Jurídico, o fundamento de validade do Direito é estritamente formal, e sua adequação indeterminada. Logo, para que o Pós-positivismo consolide-se, deverá galgaruma determinação legítima para o Direito no caso concreto, sem, contudo, reduzir-se aos preceitos jusnaturalistas. Entendamos melhor a situação.

A fundamentação jusnaturalista do Direito foi estritamente material, tendo em vista que o Direito Positivo, para que fosse válido, deveria estar em conformidade com os preceitos do Direito Natural.

Essa concepção acerca do Direito sustentou-se enquanto havia certa homogeneidade moral na sociedade (crenças, costumes, visões de mundo partilhados), vindo sucumbir diante da já mencionada Escola da Exegese, que posteriormente fora sucedida pelo Positivismo Jurídico, devido à pluralidade de características de uma nova sociedade que se formou.

Os preceitos jusnaturalistas no que tange o fundamento de validade do Direito (material) tornaram-se insustentáveis, cabendo ao Positivismo Jurídico demonstrar seu caráter dogmático e absoluto, que em uma sociedade pluralista como a contemporânea nada mais seria que arbitrar as visões de mundo de uma minoria sobre as da maioria.

Nesse contexto, a proposta Positivista apresenta um fundamento formal de validade para o Direito, pregando sua neutralidade, ou seja, sua 
desvinculação a uma moral determinada (relativismo).

Ocorre que, como essa validade é formal, é indeterminada. E como outrora demonstramos nos pensamentos de Kelsen e Hart, há casos em que o aplicador do Direito deverá transcender a lei para julgá-lo, e havendo uma indeterminação quanto à validade do Direito, o controle da discricionariedade do julgador quando de sua aplicação resta prejudicado.

Identificado o problema da validade formal no Positivismo Jurídico, bem como o do poder discricionário do julgador, ao final do século XX, vislumbrou-se a necessidade da elaboração de uma teoria que demonstre qual deva ser o conteúdo legítimo do Direito e que não imponha a visão de mundo de poucos a uma maioria.

Surge então o denominado pós-positivismo jurídico, no qual podemos colocar Robert Alexy, que apresenta interessante solução para o problema da conciliação entre legalidade e legitimidade no Direito.

Para Alexy, a despeito das teorias positivistas separarem Direito e moral, por meio de um conceito de Direito com validade puramente formal, corroborada pela legalidade em conformidade com o ordenamento e a eficácia social, as teorias não-positivistas tendem a vinculá-los (Direito e moral), concebendo o autor um conceito de Direito carreado de um terceiro aspecto além dos dois primeiros, vale dizer, o da correção material. ${ }^{7}$

Para o autor:

o direito é um sistema de normas que (1) formula uma pretensão de correção, (2) consistindo na totalidade das normas que pertencem a uma Constituição geralmente eficaz e que não são extremamente injustas, bem como à totalidade das normas promulgadas de acordo com esta Constituição, que possuem um mínimo de eficácia social ou de probabilidade de eficácia e não são extremamente injustas a qual (3) pertencem princípios e outros argumentos normativos nos quais se apoia o procedimento de aplicação do Direito e/ou tem que se apoiar a fim de satisfazer a pretensão da correção (ALEXY, 2004, p. 123).

Com esses ditames, Alexy enfatiza, primeiramente, que um sistema desprovido de pretensão à correção não possa ser considerado sistema jurídico, $\mathrm{e}$ que na prática os sistemas jurídicos a formulam. Posteriormente, que os elementos outrora descritos (legalidade em conformidade com o ordenamento, eficácia social e a correção material) referem-se além da Constituição, às normas postas em conformidade com essa Constituição, existindo uma estrutura escalonada, excluindo-se normas extremamente injustas da seara do Direito. E por fim, que incorpora-se ao Direito o procedimento de sua aplicação, pois tudo aquilo em

\footnotetext{
A respeito (Idem, p. 13-14).
} 
que se apoia ou que tem que se apoiar alguém que aplica o Direito almejando sua correção o Direito abarca. Ou seja, que princípios não identificados como jurídicos sobre as bases da validade de uma Constituição bem como demais argumentos normativos fundamentadores de decisões pertenceriam ao Direito. ${ }^{8}$

Se não estivermos enganados, Alexy considera Direito e moral como "aliados". Aliados estes que, por meio de princípios, bem como de argumentação jurídica, buscam uma aplicação justa para o Direito.

Antes de chegarmos ao findo momento desta digressão, necessitaremos pontuar alguns aspectos que envolvem as teorias dos princípios e da argumentação jurídica de Alexy.

Alexy concebe princípios e regras como espécies de normas jurídicas, por mais que sejam distintos. Para ele, as regras são aplicáveis na maneira do "tudo ou nada". ${ }^{9}$ Vale dizer, se uma regra é válida, deverá ser aplicada na sua totalidade. Em se tratando de um conflito entre regras, para que apenas uma delas seja considerada válida, deveremos tomar alguns cuidados, pois se considerarmos determinada regra como válida a fim de aplicá-la ao caso, como consequência, além da desconsideração da outra regra pela decisão, sua invalidade será declarada, a não ser que essa regra encontre-se em uma situação que excepcione a outra. ${ }^{10}$

Os princípios, de outro modo, são normas que ordenam que algo se realize na maior medida possível, em relação às possibilidades jurídicas e fáticas. São, por conseguinte, mandamentos de otimização, caracterizados pela possibilidade de satisfação em diferentes graus e de acordo com as aduzidas possibilidades fáticas e jurídicas. ${ }^{11}$

Podemos encará-los como razões em favor de determinado posicionamento argumentativo, atribuindo-se peso, à luz do caso concreto, quando de uma colisão:

As colisões entre princípios devem ser solucionadas de forma completamente diversa. Se dois princípios colidem - o que ocorre, por exemplo, quando algo é proibido de acordo com um princípio e, de acordo com outro, permitido--, um dos princípios terá que ceder. Isso não significa, contudo, nem que o princípio cedente deva ser declarado inválido, nem que nele deverá ser introduzida uma cláusula de exceção. Na verdade, o que ocorre é que um dos princípios tem precedência em face do outro sob determinadas condições. Sob outras condições a questão da precedência pode ser resolvida de forma oposta. Isso é o que se quer dizer

\footnotetext{
8 Nesse sentido (ALEXY, 2004, p. 123-126).

9 Ronald Dworkin também menciona esta diferença, mas de forma distinta. O que não enfrentaremos neste ensaio devido à delimitação de seu tema.

${ }^{10}$ ALEXY, 2008, p. 92-93.

11 Idem, p. 90.
} 
quando se afirma que, nos casos concretos, os princípios têm pesos diferentes e que os princípios com maior peso têm precedência [...] (ALEXY, 2008, p. 93-94).

Importante frisarmos, nas palavras ora mencionadas, que antecipadamente nenhum princípio tem primazia sobre os demais, e que, o uso da ponderação torna possível vislumbrar-se o maior peso de um princípio com relação a outro em dado caso, sem que haja a invalidação do princípio tido como de peso menor. Ademais, em outro caso, poderá haver a redistribuição dos pesos de uma maneira distinta, inclusive oposta.

Isso se dá por que, segundo Alexy, os princípios equiparam-se a valores, apesar de não tratarem-se destes. Para o professor, princípios dizem respeito a um conceito deontológico (de dever ser), enquanto que os valores atinem a um conceito axiológico (de bom, de melhor), não obstante estarem intimamente ligados, possibilitando-se colisão bem como sopesamento tanto de princípios como de valores, vez que a realização gradual dos princípios corresponde à dos valores. ${ }^{12}$

Alexy delimita que a visão do nível dos princípios mostra que neles estão reunidas coisas extremamente diversas. Mas mais importante que referir-se a essa diversidade é a constatação de sua indeterminação. Pois, no mundo dos princípios, há lugar pra muita coisa, podendo-se chamá-lo de mundo do dever-ser ideal. Para ele, as colisões, tensões, conflitos, etc, surgem exatamente no momento em que se tem de passar do espaçoso mundo do dever-ser ideal para o estreito mundo do dever-ser definitivo ou real. ${ }^{13}$

Mas os princípios por si só, não têm a possibilidade de determinar a resposta correta para cada caso, necessitando de um "amparo" para que alcance a aplicação racional do Direito.

Alexy então, na busca dessa aplicação racional do Direito, elabora uma teoria da argumentação jurídica, identificando-a como um caso especial da argumentação prática geral (da argumentação moral), que conjuntamente com as regras e princípios formam um procedimento, apto a estabelecer a melhor decisão para o caso concreto. ${ }^{14}$

\section{Conclusão}

Sabemos que a teoria de Alexy sofreu e sofre muitas críticas. Mas reconhecemos como inoportuno, neste momento, tecer comentários a respeito, por tratar-se nossa meta, em verdade, de outra seara bem mais humilde.

\footnotetext{
12 ALEXY, 2008, p. 144-145.

13 Idem, p. 139.

14 ALEXY, 2001, p. 267.
} 
Viemos aqui para analisar a proposta Pós-positivista, que pretende resolver o problema legado do Positivismo Jurídico, que apesar de reconhecer a discricionariedade do julgador não a resolveu, além do que envolve a aplicação do Direito no caso concreto.

Ao que parece, obteve sucesso Alexy nessa jornada. Pois impossibilitado no mundo contemporâneo, devido à pluralidade cultural e subjetiva, de apontar uma moral determinada (o que seria arbitrário), com sua regra procedimental, com primazia nos princípios e na argumentação jurídica, apontou considerável alternativa na busca da resolução racional do caso concreto.

Entendemos que o mundo contemporâneo, por sua diversidade e complexidade, dificulta a conquista da conciliação entre validade formal (legalidade) e validade material (legitimidade). Vemos, todavia, que a única solução para esta conquista reside no procedimento do Direito, que carreado por igualdade entre as partes, ampla defesa e contraditório, argumentação jurídica, produção de provas e ênfase na efetividade dos princípios jurídicos, galgará a legítima aplicação da lei no caso concreto.

\title{
Post-positivism and legal argument: reflection in the light of the concept of law
}

\begin{abstract}
The article aims to analyze today's proposal of reconciling formal validity and substantive validity (legitimacy). With this intent, we will approach the Positivist and Post-positivist theories of law, permeating the dictates of the Exegetic School, demonstrating that the concept of law has changed according to the paradigm adopted. The latter regarded the law as a complete science, without gaps, able to solve all the facts of life through the literal application of the law. The first succeeded it with a new proposal, evidencing the discretionary application of the law, as well as its indeterminacy. The second, in turn, proposes to solve problems involving the discretional power of the judge and the indeterminacy of law, not solved by the first. In this sense, we raise the theory put forward by Robert Alexy, who based on the role played by principles and legal argument, sees the procedure of law as part of its concept.
\end{abstract}

Keywords: Post-positivism. Discretional power. Determination of law. Principles. Legal argument. 


\section{REFERÊNCIAS}

ALEXY, Robert. Teoria dos direitos fundamentais. 5. ed. São Paulo: Malheiros, 2008.

. Teoria da argumentação jurídica. São Paulo: Landy, 2001. 2004.

. El concepto y la validez del derecho. Barcelona: Gedisa,

BARROSO, Luís Roberto (org.). A nova interpretação constitucional: ponderação, direitos fundamentais e relações privadas. 2. ed. Rio de Janeiro: Renovar, 2006.

KELSEN, Hans. Teoria pura do direito. 7. ed. São Paulo: Martins Fontes, 2006.

HART, H. L. A. O conceito de direito. São Paulo: Martins Fontes, 2009.

Recebido: agosto/2010. Aprovado: abri1/2013. 